\title{
Expression of growth differentiation factor 9, bone morphogenetic protein 15, and anti-Müllerian hormone in cultured mouse primary follicles
}

\author{
J C Sadeu, T Adriaenssens and J Smitz \\ Follicle Biology Laboratory, Vrije Universiteit Brussel (VUB), Laarbeeklaan 101, 1090 Brussels, Belgium \\ Correspondence should be addressed to J C Sadeu; Email: vsadeu@yahoo.co.uk
}

\begin{abstract}
Growth differentiation factor 9 (GDF9), bone morphogenetic protein 15 (BMP15), and anti-Müllerian hormone (AMH) play an important role in the primary to secondary follicle transition and follicle activation in vivo. In organ culture of neonatal mouse ovaries, it was observed that significantly fewer primary follicles develop to the secondary stage. The objectives of this study were: (1) to compare ovarian follicular populations between organ-cultured neonatal mouse ovaries and freshly isolated age-matched control ovaries; (2) to quantify RNA levels of Gdf9, Bmp15, and Amh in cultured primary follicles; and (3) to immunolocalize GDF9 and AMH in cultured ovaries. Ovaries from 3-day-old (PND 3) mice were cultured for 7 or 10 days in the absence or presence of FSH. Follicular populations were counted in freshly isolated 13-day-old (PND 13) ovaries and organ-cultured ovaries. Transcripts were quantified in isolated primary follicles using real-time RT-PCR, and protein expressions were localized using immunohistochemistry. The number of secondary follicles in organ-cultured ovaries was significantly lower than in vivo controls. Gdf9 and Bmp15 mRNA expression levels were similar as in controls. Amh mRNA levels were significantly $(P<0.05)$ lower after day 10 of culture in the absence of FSH. GDF9 and AMH proteins were respectively detected in the oocytes and the granulosa cells (GC) beginning at the primary and primordial stages onward. GDF9 and BMP15 production in cultured primary follicles are not different from in vivo controls; hence abnormal early follicular growth was not related to a deficient transcription of these factors.
\end{abstract}

Reproduction (2008) 136 195-203

\section{Introduction}

Primordial follicles are the stock from which all growing follicles are derived. Initiation of ovarian follicular (follicle activation) growth is characterized by morphological changes in primordial follicles, which include: transformation of the flattened granulosa cells (GC) into cuboidal cells, proliferation of GC, and oocyte growth. Only about $0.1 \%$ of primordial follicles that initiate growth will ever proceed to ovulation, the vast majority of growing follicles undergoing atresia (Hsueh et al. 1994). The primary to secondary follicle transition seems to be a bottleneck in the culture systems of different species (Wandji et al. 1996, 1997, Fortune et al. 1998, Hovatta et al. 1999, Yu \& Roy 1999, Devine et al. 2002, Hreinsson et al. 2002, Otala et al. 2002, Schmidt et al. 2005, Sadeu et al. 2006, Yang \& Fortune 2006, Sadeu \& Smitz 2008) in the prospect of increasing reproductive efficiency, and hopefully to help infertile women after gonadotoxic treatment.

Over the past years, the growth of rodent (Eppig \& O'Brien 1996, Parrott \& Skinner 1999, Klinger \& de Felici 2002, Obata et al. 2002, Kezele \& Skinner 2003, O'Brien et al. 2003, Lee et al. 2004, Nilsson \& Skinner 2004, Shen et al. 2006a, 2006b, 2007), cattle (Wandji et al. 1996,
Braw-Tal \& Yossefi 1997, Fortune et al. 1998), and primate (Wandji etal. 1997), including human (Hovatta etal. 1999, Wright et al. 1999, Hreinsson et al. 2002, Sadeu et al. 2006) primordial follicles has been investigated in vitro. In these ovarian culture experiments, primordial follicles within newborn or neonatal mouse ovaries, ovarian cortex of fetal or adult bovine ovaries as well as fetal baboon ovaries, or fetal or adult human ovaries were able to initiate growth and to develop to primary or secondary follicles. But generally, only a few growing primary follicles progressed to the secondary stage in cattle, primates, and humans. Meiotically competent oocytes have been mainly obtained after isolation and in vitro growth of mouse primary or secondary follicles as single functional units (Spears et al. 1994, Cortvrindt et al. 1996, Eppig \& O'Brien 1996, O'Brien et al. 2003, Lenie et al. 2004, Kreeger et al. 2005, Shen et al. 2006b, 2007). Regarding the production of mature oocytes in vitro, there is scarce proof of concept in the non-rodent species (Hirao et al. 1994).

It is known that the primary to secondary transition is induced by an autocrine/paracrine regulatory process that involves growth factors produced by the oocyte and GC. Growth differentiation factor-9 (GDF9) and bone 
morphogenetic protein 15 (BMP15) are oocyte-specific proteins secreted by growing oocytes in rodents, sheep, and humans (McGrath et al. 1995, Dube et al. 1998, Fitzpatrick et al. 1998, Aaltonen et al. 1999, Bodensteiner et al. 1999, Otsuka et al. 2000). They are known to control folliculogenesis by acting on GC in developing follicles. Studies in genetic mutations have elucidated the role of these proteins in regulating the primary to secondary follicle transition. Mutations in GDF9 (Dong et al. 1996) and BMP15 (Galloway et al. 2000, Hanrahan et al. 2004) result in growth arrest at the primary stage. Furthermore, consistent with its role in controlling follicular growth, GDF9 has been shown to enhance the development and growth of human (Hreinsson et al. 2002), and rodent (Hayashi et al. 1999, Nilsson \& Skinner 2002) early-stage follicles when added to culture media.

BMP15 and GDF9 play a synergistic role in folliculogenesis. Mice lacking both copies of the Bmp15 gene and one copy of the Gdf9 gene show increased oocyte loss and decreased late-stage follicles, whereas those lacking both copies of Gdf9 and Bmp15 genes show follicle growth arrests at the primary stage similar to the Gdf9 knockout mice (Yan et al. 2001).

Anti-Müllerian hormone (AMH) is expressed postnatally by the GC of developing follicles from the early primary stage (oocyte surrounded by a mixture of flattened and cuboidal GC) to the early antral stage (Durlinger et al. 2002a, 2002b). Increased levels of $\mathrm{AMH}$ secreted by growing follicles have been associated with the decreased activation of the pool of primordial follicles (Behringer et al. 1990). It is proposed that $\mathrm{AMH}$ inhibits the primordial to primary transition. In addition, a homozygous mouse knockout model for AMH shows an early depletion of the primordial follicle pool that is consistent with the role of $\mathrm{AMH}$ in regulating the activation of primordial follicles (Durlinger et al. 1999).

GDF9, BMP15, and AMH are major regulators for the growth and function of ovarian follicles, and it was questioned whether in the in vitro culture situation the actions of these factors might be altered in comparison with their observed roles in vivo, where they decrease the number of secondary follicles. Therefore, to investigate whether the decrease in the number of growing follicles was related to any abnormal level of expression of mRNAs for GDF9, BMP15, and $\mathrm{AMH}$, primary follicles were isolated from cultured intact neonatal mouse ovaries and used to address the question. The aims of the study were: (1) to compare the ovarian follicular population between cultured neonatal mouse ovaries and freshly isolated agematched ovaries; (2) to quantify mRNA of key growth factors in activated follicles in relation to the stage they have reached in vitro; and (3) to immunolocalize GDF9 and $\mathrm{AMH}$ in cultured ovaries.

\section{Results}

\section{Follicular development in vivo and in vitro}

Gross morphological examination of ovaries cultured in the presence of follicle-stimulating hormone (FSH) showed similar stages of follicle development compared with those cultured without FSH. In that respect, the ovaries cultured for 10 days in the absence of FSH were used to quantify ovarian follicular populations. Follicular development in vitro was evaluated by comparing both the developmental stages of the follicles and the number of different stages of follicles between PND 3 ovaries cultured for 10 days and freshly isolated ovaries of agematched PND 13 mice (Table 1).

Before culture, the ovaries of PND 3 mice mainly contained primordial follicles (Fig. 1A and B). But after 10 days of culture, there was also the appearance of early and small secondary follicles (Fig. 1C and D) besides primordial and primary follicles. Ovarian and follicular morphologies in the histological sections demonstrated the viability of the organ after culture (Fig. 1D). The growing follicles were mostly concentrated in the central part of the cultured ovary. In in vivo ovaries, they were uniformly distributed (Fig. 1F). The mean number of healthy primordial, primary, and early secondary follicles was not statistically $(P>0.05)$ different between PND 3 ovaries cultured for 10 days and control PND 13 ovaries (in vivo). However, there were significantly fewer small secondary follicles in cultured ovaries, compared with in vivo ovaries (Table 1). By normalizing to percentages, the number of small secondary follicles in the cultured ovary was about $4.8 \pm 1.5 \%$ of that of the in vivo ovary. Furthermore, in contrast to the cultured ovary, a more advanced stage of follicle development (medium secondary follicle) was found in the in vivo ovary. (Fig. 1E and F). There was no statistical difference in the number of atretic follicles between in vivo and in vitro cultured ovaries (Table 1).

Table 1 Early follicular development in PND 3 mouse ovaries after 10 days of culture, compared with 13 days in vivo (PND 13 ovaries).

\begin{tabular}{lcccccc}
\hline & \multicolumn{5}{c}{ Follicle stage (mean \pm S.E.M.) } \\
\cline { 2 - 6 } Ovaries $(n)$ & Primordial & Primary & Early secondary & Small secondary & Medium secondary & Atretic \\
\hline In vivo (5) & $5082.0 \pm 887.8$ & $103.0 \pm 19.3$ & $28.4 \pm 3.8$ & $73.0 \pm 5.6^{\mathrm{a}}$ & $35.8 \pm 6.6^{\mathrm{a}}$ & $65.2 \pm 10.7$ \\
Culture (13) & $4227.7 \pm 607.7$ & $169.2 \pm 22.5$ & $21.0 \pm 3.3$ & $3.5 \pm 1.1^{\mathrm{b}}$ & $0.0 \pm 0.0^{\mathrm{b}}$ & $86.2 \pm 18.7$ \\
\hline
\end{tabular}

Values with different superscript letters within the same column are significantly different $(P<0.0001)$. 

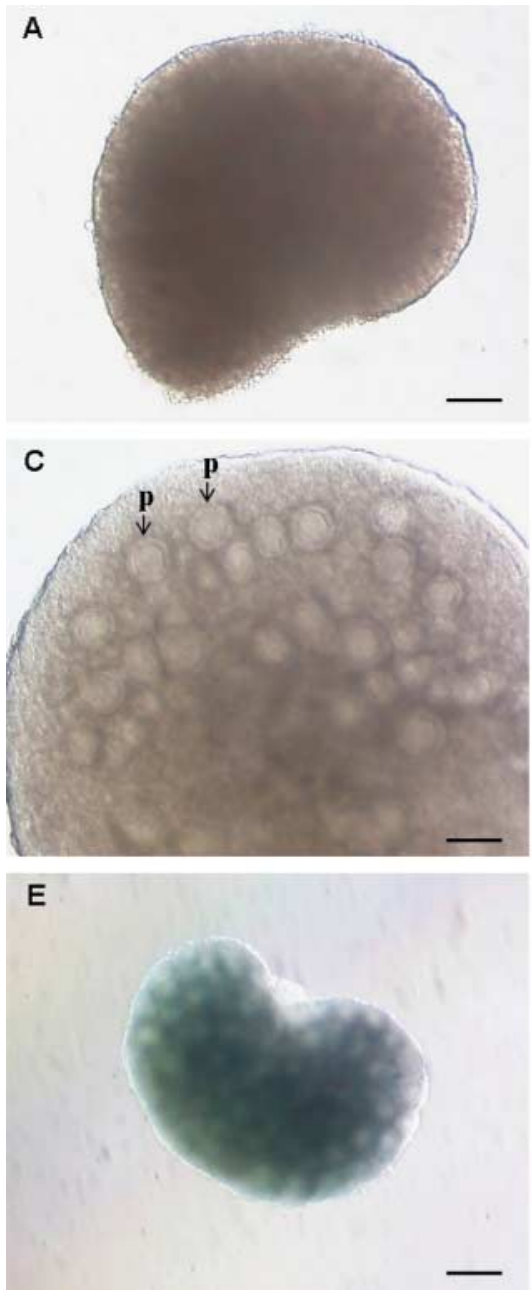
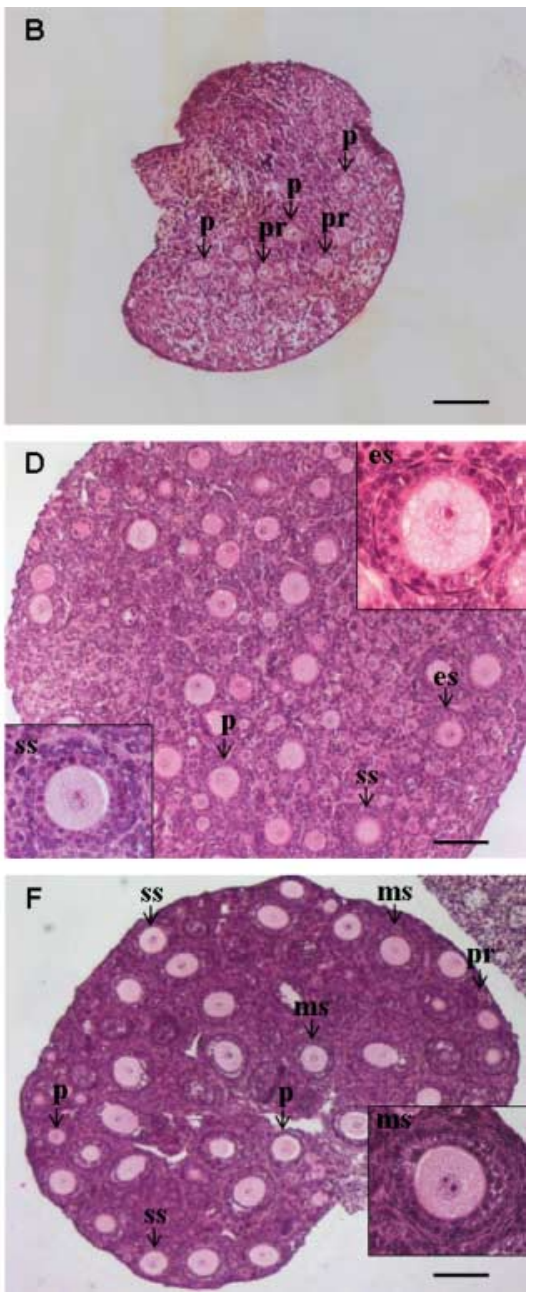

Figure 1 Photographs of freshly isolated as well as cultured mouse ovaries and the corresponding representative ovarian sections. (A and B) Freshly isolated PND 3 mouse ovary with many primordial (pr) and a few primary (p) follicles. (C and D) PND 3 mouse ovary after culture in vitro for 10 days with many primary ( $p$ ), early secondary (es + right inset), and a few small secondary (ss + inset) follicles. (D) Growing follicles are mostly found in the central part of the ovary. (E and F) Freshly isolated PND 13 mouse ovary with many primary (p), early secondary (es), small secondary (ss), and medium secondary (ms + inset) follicles. (F) Most small secondary follicles are found at the periphery of the ovary, and the medium secondary follicles at the center. Scale bars represent: (A, B, E, and F) $100 \mu \mathrm{m}$ and (C and D) $40 \mu \mathrm{m}$.

\section{Expressions of Gdf9, Bmp15, and Amh mRNAs in mouse follicles}

To investigate whether the decrease in the number of growing follicles was reflected in the expression levels of growth-related factors, oocyte-specific markers (GDF9 and BMP15) and GC marker (AMH) were examined using real-time PCR. The gene expression analysis was performed on RNA from 13 groups of primary follicles $(88-100 \mu \mathrm{m} ; n=46)$ from freshly isolated PND 13 ovaries (controls) and 38 groups of primary follicles (50-95 $\mu \mathrm{m} ; n=16$ (D7); $n=14$ (FSH D7); $n=59$ (D10); $n=50$ (FSH D10)) (Fig. 2) from cultured PND 3 ovaries. Gdf9 mRNA expression was present in all samples analyzed. In the cultured follicles, a trend towards an increase $(P=0.09)$ in the mRNA expression level from D7 to D10 was found for Gdf9 and Bmp15 (Fig. 3). There was no difference in mRNA expression level of both oocyte-specific markers (Gdf9 and Bmp15) at D10 for follicles cultured in the absence or presence of $\mathrm{FSH}$, compared with the in vivo controls (Fig. 3).

Quantitative analysis revealed that Amh mRNA expression was present in all samples analyzed. The mRNA expression level increased from D7 to D10 but did not change between the different culture conditions within D7 or D10 (Fig. 3). In the follicles cultured for 7 and 10 days in the absence of FSH, a five- and two-fold significantly $(P<0.05)$ lower Amh mRNA expression was found respectively, compared with the in vivo controls.
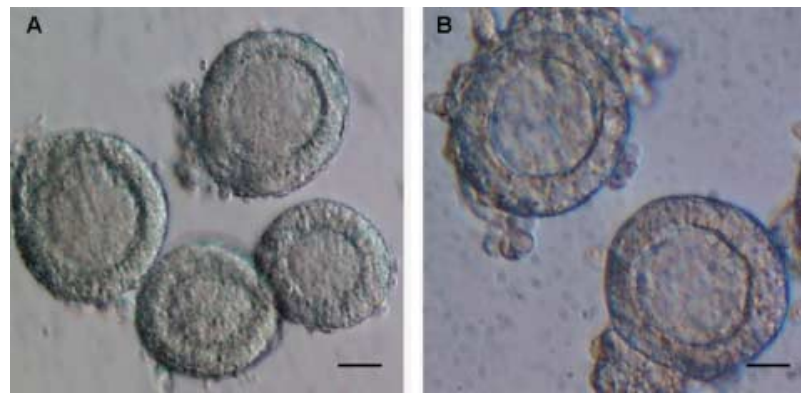

Figure 2 Morphological characteristics of in vivo and in vitro grown mouse primary follicles. (A) Primary follicles freshly isolated from PND 13 ovaries. (B) Primary follicles isolated from PND 3 ovaries cultured in vitro for 10 days. Bars $=20 \mu \mathrm{m}$. 


\section{Localization of GDF9 protein in cultured mouse ovaries}

The ovaries cultured in the absence of FSH for 10 days were further used for immunohistochemical analysis.
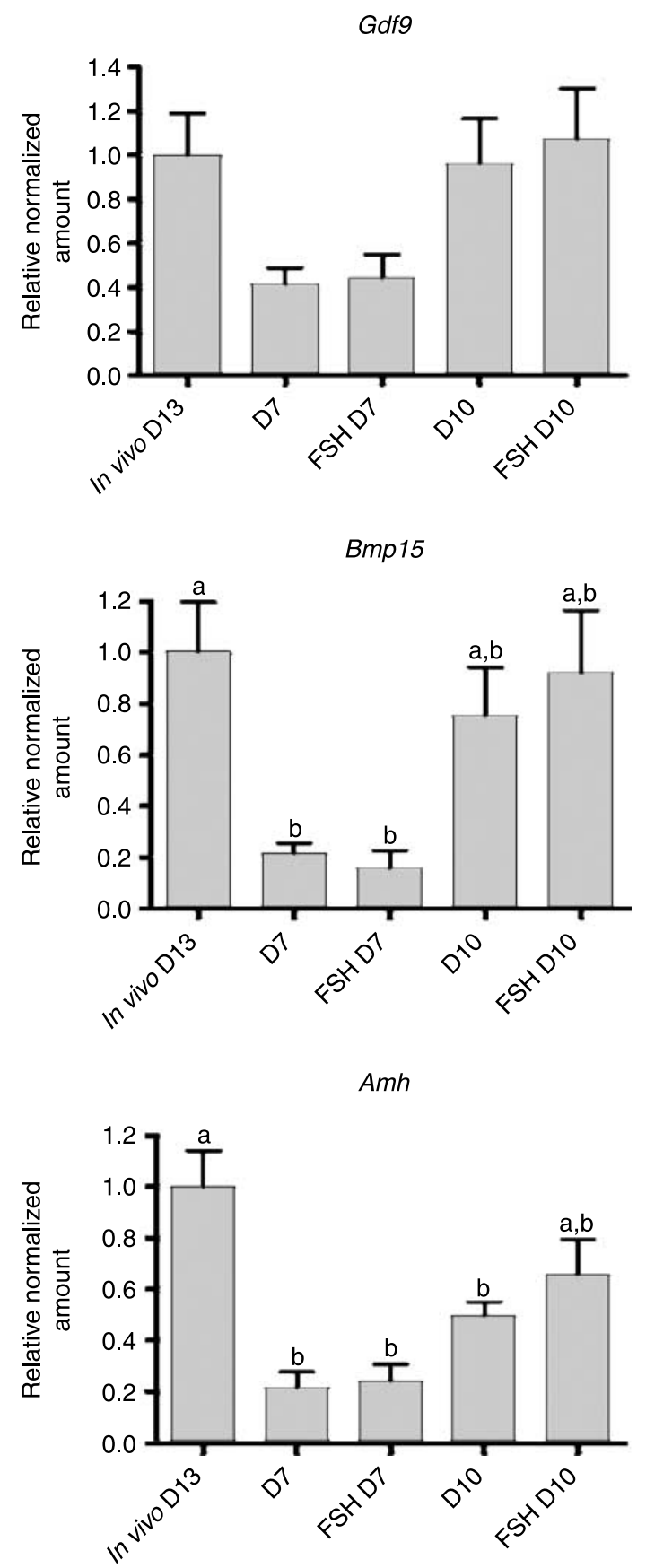

Figure 3 Expression levels of Gdf9, Bmp15, and Amh mRNAs during mouse primary follicle growth in vivo and in vitro. Gdf9, Bmp15, and Amh mRNAs were measured in freshly isolated primary follicles (in vivo D13) and in primary follicles isolated after 7 (D7) and 10 days (D10) of ovary organ culture in the absence (D7 and D10) or presence (FSHD7 and FSH D10) of FSH. Normalized values are represented with the average expression in vivo (In vivo D13) as a calibrator. Values are means \pm s.E.M. $n=13$ (in vivo), 6 (D7), 5 (FSHD7), 13 (D10), and 14 (FSHD10). Bars with different letters are significantly different $(P<0.05)$.
A weak to strong immunostaining for GDF9 was detected in the oocytes. The immunostaining was weak in primary follicles (Fig. 4A and C) and absent in primordial (pr) follicles (Fig. 4E) and some primary follicles (Fig. 4C; Table 2). No staining was found in the negative control sections (Fig. 4G).

\section{Localization of $A M H$ protein in cultured mouse ovaries}

AMH protein expression was detected in cuboidal GC. The immunoreactivity was absent in primordial follicles surrounded with flattened GC (Fig. 4F; Table 2) but present in cuboidal GC of primordial follicles
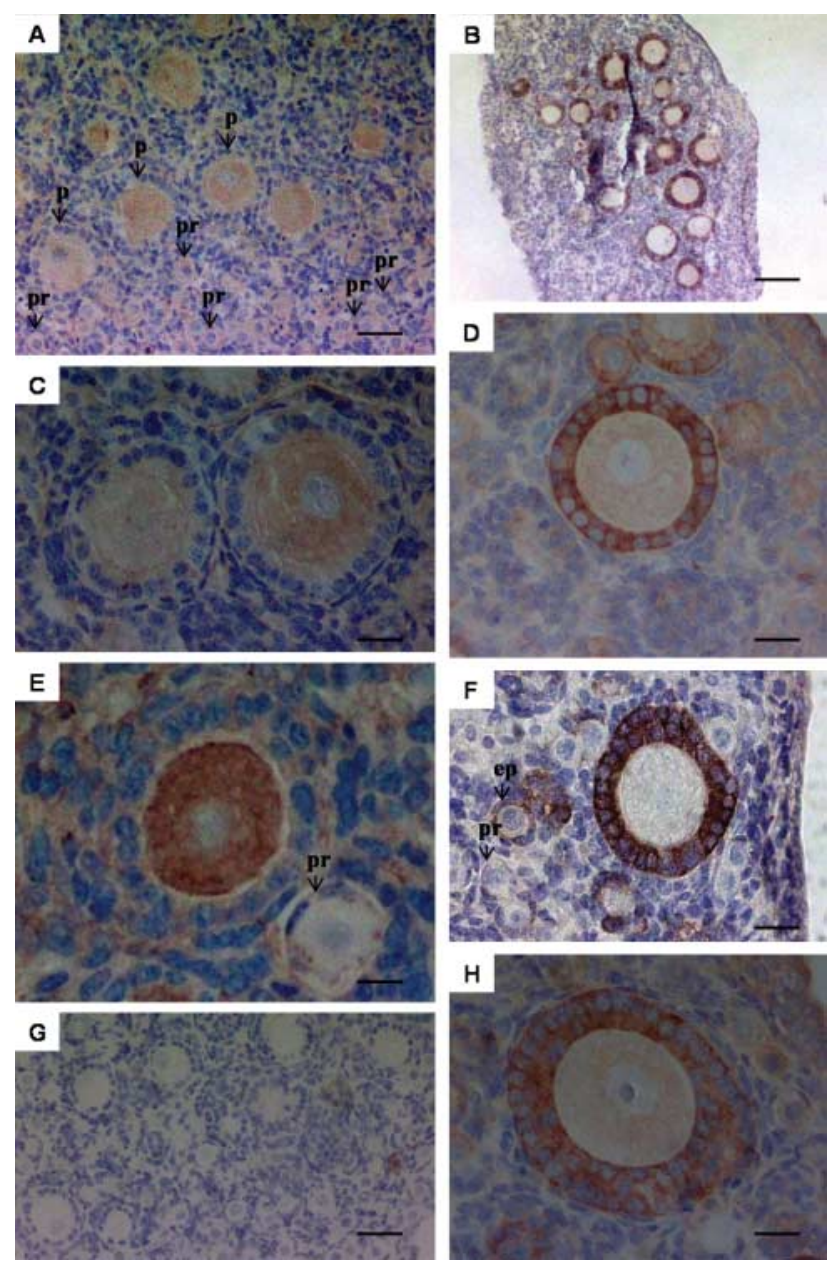

Figure 4 Representative tissue sections of cultured mouse ovaries showing an absence of GDF9 expression in (A and E) primordial (pr) follicles and positive expression in (A and C) primary ( $p$ ) and (E) early secondary follicles. Note the $(\mathrm{C})$ weak and $(\mathrm{E})$ strong intensity of the staining in oocyte. AMH expression is absent in (F) primordial (pr) follicles with one layer of flattened GC, while present in (F) primordial (ep) follicles with a mixture of flattened and cuboidal GC, (B and D) primary, (F) early secondary, and (H) small secondary follicles. (G) Negative control. Scale bars represent: (A and G) $40 \mu \mathrm{m}$, (B) $100 \mu \mathrm{m}$, and $(\mathrm{C}-\mathrm{F}$, and $\mathrm{H}) 10 \mu \mathrm{m}$. 
Table 2 Expression of growth differentiation factor 9 (GDF9) and antiMüllerian hormone (AMH) proteins in PND 3 mouse ovary after 10 days of culture.

\begin{tabular}{llllll}
\hline & $\begin{array}{c}\text { GDF9 immunopositive } \\
\text { follicles/counted } \\
\text { follicles }\end{array}$ & & \multicolumn{2}{c}{$\begin{array}{c}\text { AMH immunopositive } \\
\text { follicles/counted } \\
\text { follicles }\end{array}$} \\
\cline { 2 - 3 } \cline { 5 - 6 } Follicle stage & $n$ & $(\%)$ & & $n$ & $(\%)$ \\
\hline $\begin{array}{l}\text { Primordial (with } \\
\quad 0 / 351\end{array}$ & 0.0 & & $0 / 1173$ & 0.0 \\
$\begin{array}{l}\text { flattened GC) } \\
\text { Primary }\end{array}$ & $27 / 32$ & 84.4 & & $64 / 64$ & 100 \\
$\begin{array}{l}\text { Early secondary } \\
\text { Secondary }\end{array}$ & $4 / 4$ & 100 & & $26 / 26$ & 100 \\
\hline
\end{tabular}

$N=5$ ovaries, one from each animal; 4-5 (AMH) and 2 (GDF9) sections for each ovary were analyzed.

surrounded with a mixture of flattened and cuboidal GC (Fig. 4F). AMH immunostaining was present in GC in all the primary, early secondary, and secondary follicles examined (Fig. 4B, D, F, and H; Table 2).

\section{Discussion}

The present study showed that the transition of the first wave of developing follicles from the primary to secondary stage was interrupted in mouse ovary organ cultures. It also showed that Gdf9 and Bmp15, but not always Amh, mRNA levels in primary follicles after culture were similar to control levels in age-matched follicles from in vivo ovaries. In addition, it was found that GDF9 protein was restricted to the oocyte from primary follicle onward and $\mathrm{AMH}$ to the cuboidal GC from primordial follicles onward as previously described (McGrath et al. 1995, Durlinger et al. 2002a, 2002b, Weenen et al. 2004, Modi et al. 2006). Taken together, the present findings indicate that the block in primary follicle growth into secondary follicles in vitro might not result from a deficient transcription of GDF9 and/or BMP15.

Because communications between oocytes and follicular cells all contribute to follicular development, any alterations in growth-supporting factors may disrupt these processes. In this study, the primordial to primary transition in vitro proceeded similar to the in vivo situation. However, the deficiency in secondary follicle development in vitro might suggest an altered hormone processing, a lack of some stage-specific growth factors in the in vitro environment, or an alteration of response of GC to oocyte-secreted factors. Given that the null mutation of the Gdf9 and Bmp15 genes (Dong et al. 1996, Galloway et al. 2000, Hanrahan et al. 2004) results in growth arrest at the primary stage in vivo, it can be postulated that low expression of Gdf9 and/or Bmp15 transcripts in vitro may contribute to the decrease in the number of small and medium secondary stage follicles observed in ovarian culture experiments. However, there is no evidence for or against this idea in the literature.
Freshly isolated ovaries at PND 3 contained mostly primordial follicles. A low number of these follicles activated in vitro during whole-ovary organ culture, similar to previously described observations (Eppig \& O'Brien 1996). No significant change in the rate of development of primary and early secondary follicles was found between in vivo control and cultured ovaries although there was a trend towards increased primary follicle development in vitro. Follicle development in vivo was different from in vitro conditions in that the number of small secondary follicles was significantly increased in vivo. In addition, the development of medium secondary follicles did not occur in vitro. These findings show that most of the primordial follicles that initiated growth in vitro underwent developmental arrest at the primary stage. The number of atretic follicles was comparable between the in vivo and in vitro conditions, suggesting that atresia was not affected by the conditions of culture. Similar to the results with rodents, human, bovine, and baboon ovarian cortical tissue cultures showed that only a few growing primary follicles progress to the secondary stage (Wandji et al. 1996, 1997, Braw-Tal \& Yossefi 1997, Fortune et al. 1998, Hovatta et al. 1999, Wright et al. 1999, Hreinsson et al. 2002, Sadeu et al. 2006).

Gene expression in ovarian organ culture experiments is regularly performed with mRNA extracted from whole ovaries. The limitation in such a methodological approach is that different follicle stages exist in the cultured ovaries and therefore it is impossible to indicate which follicle stage is showing a change in expression of any particular gene. In that respect, in contrast to other studies, the present analysis on mRNA expression in cultured ovaries was performed with RNA from a welldefined follicle class. After 10 days of culture of PND 3 mouse ovaries, the Gdf9 and Bmp15 mRNA levels in primary follicles were similar to the control levels in in vivo follicles. This observation indicates a normal expression of growth-supporting factors in vitro. On the basis of the data from in vivo studies, one would expect that normal Gdf9 and Bmp15 mRNA expression in vitro would correlate with normal primary follicle progression into the secondary stage. This was not the case in our study. Nevertheless, the decreased progression in vitro might still depend on GDF9 and BMP15 since these growth factors act as homo- or heterodimers. Their prohormones must first undergo proteolytic cleavage before they can form the bioactive dimers or it is possible that expressions of GDF9 and BMP15 receptors did not occur in present ovarian organ culture experiment.

Early-stage follicles contain growing oocytes and this may explain the increased Gdf9 and Bmp15 mRNA levels from day 7 to day 10 of culture. Interestingly, both oocytesecreted factors showed similar mRNA expression patterns. The observation that Gdf9 and Bmp15 mRNA levels are slightly higher in FSH conditions might suggest that FSH could positively regulate Gdf9 and Bmp15. Using 
total RNA from immature mouse ovaries, Guéripel et al. (2006) have observed that Bmp15 but not Gdf9 mRNA levels increased in the gonadotropin-treated immature mice. This was an in vivo study and RNA was extracted from whole ovaries.

A negative regulator of early follicular development is $\mathrm{AMH}$, which has been shown to inhibit the transition from primordial to primary follicles. An increased number of developing follicles was found in mice with null mutation of the Amh gene (Durlinger et al. 1999). The Amh mRNA level was significantly lower after 10 days of culture without FSH. However, this decrease was not reflected in the number of growing follicles, which may suggest that $\mathrm{AMH}$ expression in vitro could be high enough to keep control over follicle recruitment. By contrast, the Amh mRNA level of follicles cultured in the FSH conditions was similar with the control level in vivo, suggesting a possible direct or indirect relationship between $\mathrm{FSH}$ and $\mathrm{AMH}$. It was shown that FSH-stimulated preantral follicle growth in vitro was attenuated in the presence of $\mathrm{AMH}$ and, in addition, that more follicles start to grow in vivo under the influence of exogenous $\mathrm{FSH}$ in $\mathrm{AMH}$-deficient mice compared with the wild types (Durlinger et al. 2001). Given that Amh mRNA levels were not significantly different between the follicles cultured in the FSH and those cultured in the no FSH conditions, direct evidence to support the role of $\mathrm{FSH}$ in regulating $\mathrm{AMH}$ expression cannot be provided.

Consistent with Gdf9 and Amh mRNA expressions detected by real-time PCR, we showed by immunohistochemical analysis that GDF9 protein was first detected in oocytes of primary follicles, and $\mathrm{AMH}$, in cuboidal GC of primordial (oocyte surrounded by a mixture of flattened and cuboidal GC) follicles, suggesting that these proteins were present at these stages of follicle development as well as in the more advanced stages where positive immunoreactions were further detected. This provided evidence for the maintenance of the stagespecific specialized GC and oocyte functions during follicle growth in vitro. These findings are in agreement with previously described observations from in vivo studies where Gdf9 mRNA expression and protein were demonstrated in oocytes of primary and advanced follicle stages in mice, rats, and humans (McGrath et al. 1995, Aaltonen et al. 1999, Elvin et al. 1999, Hayashi et al. 1999, Jaatinen et al. 1999), and AMH in cuboidal GC of primordial and advanced follicle stages in mice and humans (Durlinger et al. 2002a, 2002b, Weenen et al. 2004).

In summary, primary follicles isolated from cultured PND 3 mouse ovaries were used to determine whether any alteration in the intrinsic expressions of GDF9, BMP15, and $\mathrm{AMH}$ could explain the block in follicle transition from the primary to secondary stage in ovary organ culture. It was found that no significant change in expression levels of Gdf9 and Bmp15 occurred in primary follicles grown in vitro compared with control age-matched follicles grown in vivo, whereas significantly lower Amh expression was found after in vitrogrowth in the absence of FSH. In addition, GDF9 and AMH protein expressions were detected at similar stages of follicle development as described in vivo. The present observations indicated that the disruption of the primary to secondary transition in vitro might not result from defective Gdf9, Bmp15, and/or AMH transcription. Additional investigations of other genes playing a significant role in the oocyte, GC, and theca cell interactions would provide more insight into the abnormal process of follicle development beyond the primary stage in vitro.

\section{Materials and Methods}

\section{Animals}

Female F1 hybrid (C57BL/6j $\times$ CBA/Ca) mice housed and bred according to national standards were used throughout the study. The Ethics Committee for laboratory animal experiments of Vrije Universiteit Brussel approved all procedures.

Postnatal 3-day-old (PND 3) mice were killed by decapitation. Ovaries were aseptically removed and collected in 1.5 $\mathrm{ml}$ Leibovitz-L15 medium supplemented with $10 \%$ fetal bovine serum (FBS), $100 \mu \mathrm{g} / \mathrm{ml}$ streptomycin, and $100 \mathrm{IU} / \mathrm{ml}$ penicillin. Under a light microscope, the bursa and surrounding tissues were carefully dissected away from the ovaries. The procedure was carried out at $37^{\circ} \mathrm{C}$. Unless indicated, otherwise all chemicals used were purchased from Invitrogen.

\section{Ovary organ culture}

Ovaries were cultured as described in Parrot \& Skinner (1999) with some modifications. Each well of 4-well culture plates (Nunc, VWR, Leuven, Belgium) was filled with $500 \mu$ l Dulbecco's modified Eagle's medium-Ham's F-12 (1:1, v/v) supplemented with $10 \% \mathrm{FBS}, 10 \mu \mathrm{g} / \mathrm{ml}$ insulin, $10 \mu \mathrm{g} / \mathrm{ml}$ transferrin, and without or with $50 \mathrm{mIU} / \mathrm{ml} \mathrm{FSH}$. A floating filter $(0.4 \mu \mathrm{m}$ isopore membrane filter, Millipore, Brussels, Belgium) was laid over the medium and the plates were pre-equilibrated for $\sim 4 \mathrm{~h}$. Ovaries (2-4/well) collected at PND 3 were placed onto the floating filters, covered with drops of medium, and cultured for 7 (D7) or 10 (D10) days at $37{ }^{\circ} \mathrm{C}$ in a humidified incubator with $5 \% \mathrm{CO}_{2}$ in air. Three-day-old ovaries cultured for 10 days should be comparable with ovaries of similar age (i.e., ovaries of 13-dayold mice). Consequently, a normal number of small secondary follicles (similar to the development after 13 days in vivo) should be obtained. Half the volume of culture medium was replaced with fresh pre-equilibrated medium every 3 days. At the end of cultures, the ovaries were fixed in $4 \%$ formaldehyde (Sigma) for morphological or immunohistochemical analysis. Alternatively, they were used for an isolation of primary follicles. Each experiment was performed at least three times. One group of ovaries $(n=5)$ was collected from age-matched 13-day-old (PND 13) mice for in vivo comparisons of follicular populations and another group $(n=6)$ for isolation of primary follicles for in vivo comparisons of expressions of Gdf9, Bmp15, and Amh mRNAs. 


\section{Tissue processing}

The ovaries were fixed for $\sim 4 \mathrm{~h}$ at room temperature. Subsequently, they were transferred into $70 \%$ ethanol at $4{ }^{\circ} \mathrm{C}$ until transported to the histology laboratory for processing and embedding into paraffin blocks. The ovaries were completely serial sectioned at $5 \mu \mathrm{m}$ thickness on a sliding microtome (Bromma, Stockholm, Sweden). Every other set of five consecutive sections was mounted onto a microscope slide.

\section{Quantification of primordial and primary follicles}

Thirteen cultured ovaries and five ovaries of PND 13 immature animals were used for the analysis. The sections were deparaffinized, hydrated, and stained with hematoxylin, eosin, and safran. Every tenth section was examined under a light microscope for the presence of follicles. Primordial and primary follicles were counted in the entire sections. To avoid counting the same follicle more than once, only follicles with visible oocyte nucleolus were counted.

Early-stage follicles were classified as: (a) primordial follicle, oocyte surrounded by flattened or a mixture of flattened and cuboidal GC; (b) primary follicle, oocyte surrounded by one layer of cuboidal GC; (c) early secondary follicle, oocyte surrounded by one and a half layer of GC; (d) small secondary follicle, oocyte surrounded by two layers of GC; and (e) medium secondary follicle, oocyte surrounded by two and a half to three layers of GC. Follicles were considered atretic based on the following criteria: pyknotic GC or theca cells, eosinophilia of the ooplasm, a contracted chromatin material, or loss of basement membrane integrity. The size of the ovaries did not change significantly between treatments, and an estimation of the total follicle numbers per ovary was obtained by multiplying the number of primordial or primary follicles present in every tenth section analyzed by 10 to account for the ovarian sections not included in the analysis (Flaws et al. 2001).

\section{Quantification of early, small, and medium secondary follicles}

The number of healthy early, small, and medium secondary follicles per ovary was determined by exact counts from an examination of each of the entire consecutive $5 \mu \mathrm{m}$ sections throughout the whole ovary. Attention was paid to avoid double counting in adjacent sections.

\section{Isolation of primary follicles}

Primary follicles were isolated from ovaries after 7 or 10 days of culture and from in vivo D13 ovaries (of immature mice) by mechanical isolation with fine $25 \frac{1}{2}$ gauge needles (Becton Dickinson, Erembodegem, Belgium). The diameter of the follicles was measured with a caliper in the eyepiece of an inverted microscope. A total of 185 primary follicles were isolated and immediately frozen (2-12 follicles/cryovial) in liquid nitrogen and stored until analyzed for gene expression as described below.

\section{Gdf9, Bmp15, and Amh mRNA expressions in primary follicles}

\section{RNA extraction and $R T$}

Total RNA was extracted from pooled follicles using the RNeasy Micro kit (Qiagen) according to the manufacturer's instructions. An exogenous control $10 \mathrm{pg}$ of luciferase mRNA (Promega) was added and samples were eluted in $14 \mu \mathrm{l}$ RNasefree water and stored at $-80^{\circ} \mathrm{C}$. Subsequently, RT of $10 \mu \mathrm{l}$ total RNA was carried out using the iScript cDNA Synthesis Kit (BioRad laboratories) according to the manufacturer's instructions using the blend of oligo(dT) and random hexamers in a total volume of $20 \mu \mathrm{l}$. Negative controls were generated by omitting the RNA or the RT enzyme. Reverse transcribed cDNA was diluted 2:5 with DEPC-treated water and stored at $-80{ }^{\circ} \mathrm{C}$ until real-time PCR was performed.

\section{Real-time RT-PCR}

Quantitative PCR was performed on the LightCycler 480 (Roche Diagnostics). PCR primer sequences are indicated in Table 3. Amplification reactions were carried out in a total volume of $15 \mu \mathrm{l}$ containing $2 \mu \mathrm{l}$ cDNAs, $7.5 \mu \mathrm{l}$ SYBR Green PCR Master Mix $2 \times$ (Roche Diagnostics), and $0.6 \mu \mathrm{M}$ forward and reverse gene-specific primers. Cycle amplification protocol was as follows: $95^{\circ} \mathrm{C}$ for $10 \mathrm{~min}$ followed by 55 cycles of $95{ }^{\circ} \mathrm{C}$ for $10 \mathrm{~s}$. and $60{ }^{\circ} \mathrm{C}$ for $30 \mathrm{~s}$. For the quantification, standard curves were generated by amplifying serial dilutions of each amplicon. The specificity of the PCR products was checked by the melting curve analysis performed after the amplification cycles, and was further confirmed by sequencing the amplicons. The amount of gene of interest was normalized with the amount of luciferase in the same sample and with the number of follicles in the sample. Luciferase has been used as an appropriate exogenous control gene for quantitative PCR

Table 3 Primers pairs used for real-time PCR.

\begin{tabular}{llcc}
\hline Gene & \multicolumn{1}{c}{ Sequence $\left(5^{\prime}-3^{\prime}\right)$} & Amplicon size (bp) & GenBank accession no. \\
\hline Gdf9 & F: TACCGTCCGGCTCTTCAGT & 93 & NM_008110.1 \\
Rmp15 & F: TTAAACAGCAGGTCCACCATC & 113 & NM_009757.3 \\
R: AAGTAGGCCTCCCAGAGGT & F: GGGGAGACTGGGTAACCA & 67 & NM_007445.2 \\
& R: AGAGCTCGGGCTCCCATA & & \\
\hline
\end{tabular}


studies (Pennetier et al. 2006). Each sample was tested in triplicate and the normalized expression level of each gene was then related to the average amount as found in the in vivo control samples, PND 13.

\section{Immunohistochemistry}

The sections were incubated overnight at $37^{\circ} \mathrm{C}$ and then for $2 \mathrm{~h}$ at $60{ }^{\circ} \mathrm{C}$, at which point they were deparaffinized, hydrated, and incubated with $3 \% \mathrm{H}_{2} \mathrm{O}_{2}$-methanol solution for $30 \mathrm{~min}$. Then they were rinsed with distilled water and treated in citrated buffer $\left(\mathrm{pH} \mathrm{6)}\right.$ for $20 \mathrm{~min}$ at $95^{\circ} \mathrm{C}$. After cooling the sections to room temperature, they were washed with three changes of PBS for 5 min each and preincubated with $10 \%$ normal rabbit serum for $20 \mathrm{~min}$ at room temperature, and incubated with primary antibodies overnight at $4{ }^{\circ} \mathrm{C}$ in a humidified chamber. The primary antibodies included: goat polyclonal IgG (Santa Cruz, Heidelberg, Germany) diluted to 1:50 (GDF9, sc-12244), and 1:200 (AMH, sc-6886) in PBS with 5\% BSA. After that, the sections were washed with three changes of PBS with $0.1 \%$ Triton for $5 \mathrm{~min}$ each. All other incubations and washes were done at room temperature. The sections were further incubated for $30 \mathrm{~min}$ with biotinylated polyclonal rabbit anti-goat IgG (Dako, Heverlee, Belgium) diluted to 1:200 (GDF9) and 1:400 (AMH) in PBS with 5\% BSA. Next, the sections were washed with three changes of PBS with $0.1 \%$ Triton for 5 min each, before being incubated for 30 min with extravidin diluted to 1:200 in PBS. Afterwards, the sections were then washed with three changes of PBS for 5 min each. Binding of the primary antibody was detected with diaminobenzidine (DAB; Sigma) solution $(0.7 \mathrm{mg} / \mathrm{ml})$ according to the manufacturer's instructions. The sections were washed with running and distilled water and then incubated with $\mathrm{CuSO}_{4}$ for 5 min before being washed again with distilled and running water. The nuclei were counterstained with hematoxylin. Labeled cells were distinguished from unlabeled ones based upon the brown DAB precipitate. The primary antibodies were replaced by the antibody diluents in negative control sections. Negative controls were included in each run. Five cultured ovaries from five animals were used and two to five sections for each ovary were analyzed. Sections immunostained for GDF9 and AMH proteins were examined for the percentage of labeled follicles relative to the total number of follicles to assess growth factor expression.

\section{Statistical analysis}

All data are expressed as mean \pm S.E.M. Statistical analysis of follicle number was performed by Student's $t$-test and the differences in Gdf9, Bmp15, and Amh mRNA levels between control and cultured groups were determined by one-way ANOVA followed by Tukey's post hoc test. The GraphPad Prism 4.01 statistical analysis software (GraphPad Software Inc., San Diego, CA, USA) was used for all analysis. $P<0.05$ was considered significant.

\section{Declaration of interest}

The authors declare that there is no conflict of interest that would prejudice the impartiality of this scientific work.

\section{Funding}

The financial support from the Fund for Research Flanders (FWO-Vlaanderen), the Research Fund of the Vrije Universiteit Brussel, and the Willy Gepts Fund of the UZ Brussel are greatly acknowledged.

\section{Acknowledgements}

The authors would like to thank Kathy Billooye, research technician, for her assistance in preparation of tissue sections.

\section{References}

Aaltonen J, Laitinen MP, Vuojolainen K, Jaatinen R, Horelli-Kuitunen N, Seppä L, Louhio H, Tuuri T, Sjöberg J, Bützow R et al. 1999 Human growth differentiation factor 9 (GDF9) and its novel homolog GDF9B are expressed in oocytes during early folliculogenesis. Journal of Clinical Endocrinology and Metabolism 84 2744-2750.

Behringer RR, Cate RL, Froelick GJ, Palmiter RD \& Brinster RL 1990 Abnormal sexual development in transgenic mice chronically expressing müllerian inhibiting substance. Nature 345 167-170.

Bodensteiner KJ, Clay CM, Moeller CL \& Sawyer HR 1999 Molecular cloning of the ovine growth/differentiation factor-9 gene and expression of growth/differentiation factor-9 in ovine and bovine ovaries. Biology of Reproduction 60 381-386.

Braw-Tal R \& Yossefi S 1997 Studies in vivo and in vitro on the initiation of follicle growth in the bovine ovary. Journal of Reproduction and Fertility 109 165-171.

Cortvrindt R, Smitz J \& Van Steirteghem AC 1996 In vitro maturation, fertilization and embryo development of immature oocytes from early preantral follicles from prepuberal mice in a simplified culture system. Human Reproduction 11 2656-2666.

Devine PJ, Sipes IG, Skinner MK \& Hoyer PB 2002 Characterization of a rat in vitro ovarian culture system to study the ovarian toxicant 4 -vinylcyclohexene diepoxide. Toxicology and Applied Pharmacology 184 107-115.

Dong J, Albertini DF, Nishimori K, Kumar TR, Lu N \& Matzuk MM 1996 Growth differentiation factor-9 is required during early ovarian folliculogenesis. Nature 383 531-535.

Dube JL, Wang P, Elvin J, Lyons KM, Celeste AJ \& Matzuk MM 1998 The bone morphogenetic protein 15 gene is X-linked and expressed in oocytes. Molecular Endocrinology 12 1809-1817.

Durlinger AL, Kramer P, Karels B, de Jong FH, Uilenbroek JT, Grootegoed JA \& Themmen AP 1999 Control of primordial follicle recruitment by antiMüllerian hormone in the mouse ovary. Endocrinology 140 5789-5796.

Durlinger AL, Gruijters MJ, Kramer P, Karels B, Kumar TR, Matzuk MM, Rose UM, de Jong FH, Uilenbroek JT, Grootegoed JA et al. 2001 AntiMüllerian hormone attenuates the effects of FSH on follicle development in the mouse ovary. Endocrinology 142 4891-4899.

Durlinger AL, Visser JA \& Themmen AP 2002a Regulation of ovarian function: the role of anti-Mullerian hormone. Reproduction 124 601-609.

Durlinger AL, Gruijters MJ, Kramer P, Karels B, Ingraham HA, Nachtigal MW, Uilenbroek JT, Grootegoed JA \& Themmen AP 2002b Anti-Müllerian hormone inhibits initiation of primordial follicle growth in the mouse ovary. Endocrinology 143 1076-1084.

Elvin JA, Clark AT, Wang P, Wolfman NM \& Matzuk MM 1999 Paracrine actions of growth differentiation factor-9 in the mammalian ovary. Molecular Endocrinology 13 1035-1048.

Eppig JJ \& O'Brien MJ 1996 Development in vitro of mouse oocytes from primordial follicles. Biology of Reproduction 54 197-207.

Fitzpatrick SL, Sindoni DM, Shughrue PJ, Lane MV, Merchenthaler IJ \& Frail DE 1998 Expression of growth differentiation factor-9 messenger ribonucleic acid in ovarian and nonovarian rodent and human tissues. Endocrinology 139 2571-2578.

Flaws JA, Hirshfield AN, Hewitt JA, Babus JK \& Furth PA 2001 Effect of bcl2 on the primordial follicle endowment in the mouse ovary. Biology of Reproduction 64 1153-1159. 
Fortune JE, Kito S, Wandji SA \& Srsen V 1998 Activation of bovine and baboon primordial follicles in vitro. Theriogenology 49 441-449.

Galloway SM, McNatty KP, Cambridge LM, Laitinen MPE, Juengel JL, Jokiranta TS, McLaren RJ, Luiro K, Dodds KG, Montgomery GW et al. 2000 Mutations in an oocyte-derived growth factor gene (BMP15) cause increased ovulation rate and infertility in a dosage-sensitive manner. Nature Genetics 25 279-283.

Guéripel X, Brun V \& Gougeon A 2006 Oocyte bone morphogenetic protein 15 , but not growth differentiation factor 9 , is increased during gonadotropin-induced follicular development in the immature mouse and is associated with cumulus oophorus expansion. Biology of Reproduction 75 836-843.

Hanrahan JP, Gregan SM, Mulsant P, Mullen M, Davis GH, Powell R \& Galloway SM 2004 Mutations in the genes for oocyte-derived growth factors gdf9 and bmp15 are associated with both increased ovulation rate and sterility in cambridge and belclare sheep (ovis aries). Biology of Reproduction 70 900-909.

Hayashi M, McGee EA, Min G, Klein C, Rose UM, van Duin M \& Hsueh AJ 1999 Recombinant growth differentiation factor-9 (GDF9) enhances growth and differentiation of cultured early ovarian follicles. Endocrinology 140 1236-1244.

Hirao Y, Nagai T, Kubo M, Miyano T, Miyake M \& Kato S 1994 In vitro growth and maturation of pig oocytes. Journal of Reproduction and Fertility 100 333-339.

Hovatta O, Wright C, Krausz T, Hardy K \& Winston RM 1999 Human primordial, primary and secondary ovarian follicles in long-term culture: effect of partial isolation. Human Reproduction 14 2519-2524.

Hreinsson JG, Scott JE, Rasmussen C, Swahn ML, Hsueh AJ \& Hovatta O 2002 Growth differentiation factor-9 promotes the growth, development, and survival of human ovarian follicles in organ culture. Journal of Clinical Endocrinology and Metabolism 87 316-321.

Hsueh AJ, Billig H \& Tsafriri A 1994 Ovarian follicle atresia: a hormonally controlled apoptotic process. Endocrine Reviews 15 707-724.

Jaatinen R, Laitinen MP, Vuojolainen K, Aaltonen J, Louhio $H$, Heikinheimo K, Lehtonen E \& Ritvos O 1999 Localization of growth differentiation factor-9 (GDF9) mRNA and protein in rat ovaries and cDNA cloning of rat GDF9 and its novel homolog GDF9B. Molecular and Cellular Endocrinology 156 189-193.

Kezele P \& Skinner MK 2003 Regulation of ovarian primordial follicle assembly and development by estrogen and progesterone: endocrine model of follicle assembly. Endocrinology 144 3329-3337.

Klinger FG \& de Felici M 2002 In vitro development of growing oocytes from fetal mouse oocytes: stage-specific regulation by stem cell factor and granulosa cells. Developmental Biology 244 85-95.

Kreeger PK, Fernandes NN, Woodruff TK \& Shea LD 2005 Regulation of mouse follicle development by follicle-stimulating hormone in a threedimensional in vitro culture system is dependent on follicle stage and dose. Biology of Reproduction 73 942-950.

Lee WS, Yoon SJ, Yoon TK, Cha KY, Lee SH, Shimasaki S et al. 2004 Effects of bone morphogenetic protein-7 (BMP-7) on primordial follicular growth in the mouse ovary. Molecular Reproduction and Development 69 159-163.

Lenie S, Cortvrindt R, Adriaenssens T \& Smitz J 2004 A reproducible twostep culture system for isolated primary mouse ovarian follicles as single functional units. Biology of Reproduction 71 1730-1738.

McGrath SA, Esquela AF \& Lee SJ 1995 Oocyte-specific expression of growth/differentiation factor-9. Molecular Endocrinology 9 131-136.

Modi D, Bhartiya D \& Puri C 2006 Developmental expression and cellular distribution of Mullerian inhibiting substance in the primate ovary. Reproduction 132 443-453.

Nilsson EE \& Skinner MK 2002 Growth and differentiation factor-9 stimulates progression of early primary but not primordial rat ovarian follicle development. Biology of Reproduction 67 1018-1024.

Nilsson EE \& Skinner MK 2004 Kit ligand and basic fibroblast growth factor interactions in the induction of ovarian primordial to primary follicle transition. Molecular and Cellular Endocrinology 214 19-25.

Obata Y, Kono T \& Hatada I 2002 Maturation of mouse fetal germ cells in vitro. Nature 418 497-498.

O'Brien MJ, Pendola JK \& Eppig JJ 2003 A revised protocol for in vitro development of mouse oocytes from primordial follicles dramatically improves their developmental competence. Biology of Reproduction 68 1682-1686.
Otala M, Erkkila K, Tuuri T, Sjoberg J, Suomalainen L, Suikkari AM \& Dunkel L 2002 Cell death and its suppression in human ovarian tissue culture. Molecular Human Reproduction 8 228-236.

Otsuka F, Yao Z, Lee T, Yamamoto S, Erickson GF \& Shimasaki S 2000 Bone morphogenetic protein-15. Identification of target cells and biological functions. Journal of Biological Chemistry 275 39523-39528.

Parrott JA \& Skinner MK 1999 Kit-ligand/stem cell factor induces primordial follicle development and initiates folliculogenesis. Endocrinology $\mathbf{1 4 0}$ $4262-4271$.

Pennetier S, Perreau C, Uzbekova S, Thélie A, Delaleu B, Mermillod P \& Dalbiès-Tran R 2006 MATER protein expression and intracellular localization throughout folliculogenesis and preimplantation embryo development in the bovine. BMC Developmental Biology 626.

Sadeu JC \& Smitz J 2008 Growth differentiation factor-9 (GDF9) and anti-müllerian hormone (AMH) expression in cultured human follicles from frozen-thawed ovarian tissue. Reproductive Biomedicine Online [in press].

Sadeu JC, Cortvrindt R, Ron-El R, Kasterstein E \& Smitz J 2006 Morphological and ultrastructural evaluation of cultured frozen-thawed human fetal ovarian tissue. Fertility and Sterility 85 1130-1141.

Schmidt KL, Kryger-Baggesen N, Byskov AG \& Andersen CY 2005 AntiMullerian hormone initiates growth of human primordial follicles in vitro. Molecular and Cellular Endocrinology 234 87-93.

Shen W, Li L, Zhang D, Pan Q, Ding M \& Deng H 2006a Mouse oocytes derived from fetal germ cells are competent to support the development of embryos by in vitro fertilization. Molecular Reproduction and Development 73 1312-1317.

Shen W, Zhang D, Qing T, Cheng J, Bai Z, Shi Y, Ding M \& Deng H $2006 b$ Living offspring produced by mouse oocytes derived from premeiotic fetal germ cells. Biology of Reproduction 75 615-623.

Shen W, Li L, Bai Z, Pan Q, Ding M \& Deng H 2007 In vitro development of mouse fetal germ cells into mature oocytes. Reproduction $\mathbf{1 3 4}$ 223-231.

Spears N, Boland NI, Murray AA \& Gosden RG 1994 Mouse oocytes derived from in vitro grown primary ovarian follicles are fertile. Human Reproduction 9 527-532.

Wandji SA, Srsen V, Voss AK, Eppig JJ \& Fortune JE 1996 Initiation in vitro of growth of bovine primordial follicles. Biology of Reproduction $\mathbf{5 5}$ 942-948.

Wandji SA, Srsen V, Nathanielsz PW, Eppig JJ \& Fortune JE 1997 Initiation of growth of baboon primordial follicles in vitro. Human Reproduction 12 1993-2001.

Weenen C, Laven JS, Von Bergh AR, Cranfield M, Groome NP, Visser JA, Kramer P, Fauser BC \& Themmen AP 2004 Anti-Müllerian hormone expression pattern in the human ovary: potential implications for initial and cyclic follicle recruitment. Molecular Human Reproduction $\mathbf{1 0}$ 77-83.

Wright CS, Hovatta O, Margara R, Trew G, Winston RM, Franks S et al. 1999 Effects of follicle-stimulating hormone and serum substitution on the in vitro growth of human ovarian follicles. Human Reproduction $\mathbf{1 4}$ 1555-1562.

Yan C, Wang P, DeMayo J, DeMayo FJ, Elvin JA, Carino C, Prasad SV, Skinner SS, Dunbar BS, Dube JL et al. 2001 Synergistic roles of bone morphogenetic protein 15 and growth differentiation factor 9 in ovarian function. Molecular Endocrinology 15 854-866.

Yang MY \& Fortune JE 2006 Testosterone stimulates the primary to secondary follicle transition in bovine follicles in vitro. Biology of Reproduction 75 924-932.

Yu N \& Roy SK 1999 Development of primordial and prenatal follicles from undifferentiated somatic cells and oocytes in the hamster prenatal ovary in vitro: effect of insulin. Biology of Reproduction 61 1558-1567.

Received 11 February 2008

First decision 14 March 2008

Revised manuscript received 2 May 2008

Accepted 8 May 2008 